\title{
Morphology of the Cervical Lymph Nodes of Agouti (Dasyprocta prymnolopha, Wagler, 1831)
}

\author{
Paulo Gustavo Sedenho de Carvalho ${ }^{1}$ Sérgio Paulo Lima Guerra ${ }^{2}$ Márcia dos Santos Rizzo ${ }^{2}$ \\ Andrezza Braga Soares da Silva ${ }^{3}$ Maria Michele Araújo de Sousa Cavalcante ${ }^{3}$ \\ Airton Mendes Conde Júnior ${ }^{2}$
}

${ }^{1}$ Center of Natural Sciences, Universidade Federal do Piauí, Teresina, $\mathrm{PI}$, Brazil

2 Department of Morphology, Health Sciences Center, Universidade Federal do Piauí, Teresina, PI, Brazil

${ }^{3}$ Department of Animal Science, Center of Agrarian Sciences, Universidade Federal do Piauí, Teresina, PI, Brazil

\begin{abstract}
Address for correspondence Andrezza Braga Soares da Silva, PhD, Departamento de Ciência Animal, Centro de Ciências Agrárias, Universidade Federal do Piauí, Rua Nossa Senhora de Fátima, Iningua, Teresina, Piaui, 64049550, Brazil (e-mail: andrezzab1@hotmail.com).
\end{abstract}

J Morphol Sci 2018;35:191-193.

\begin{abstract}
Keywords

- lymph nodes

- agouti

- rodent

- dasyprocta prymnolopha

- histology

In the scientific literature, works related to the morphology and histology of agoutis, Dasyprocta prymnolopha, Wagler, 1831, approach several organs and systems. However, none referenced the lymph nodes of this animal. The objectives of the present study were to perform morphological and histological analyses, under optical microscopy, of the cranial and cervical lymph nodes of agoutis, comparing them with the typical lymph nodes of already documented animal species. In the present work, four animals were used, respecting all the ethical and legal aspects, followed by the development of methodologies related to the morphology and histology in question. The results obtained did not show significant morphological and histological differences between the cranial and cervical lymph nodes of agoutis when compared with typical lymph nodes of the animal kingdom.
\end{abstract}

\section{Introduction}

The lymphatic system corresponds to the anatomical and physiological aspects of the vessels and organs responsible for transporting the lymphatic fluid in an organism. In the lymphatic system, there are lymph nodes, organs interspersed in the lymphatic vessels pathway, which exhibit an accumulation of lymphatic tissue surrounded by elastic and smooth muscle fibers wrapped in a connective tissue capsule. ${ }^{1,2}$ According to Banks, ${ }^{3}$ the functions of these organs are to produce lymphocytes, to filter the lymph, to phagocyte strange materials, and to produce antibodies.

The lymphatic tissue consists predominantly of lymphocytes that, together with a variable number of plasma cells, macrophages, and other cells, occur between a framework of fibers and reticular cells. In hematoxylin and eosin (H\&E) preparations, the lymphatic tissue is stained purple due to the presence of numerous lymphocytes, each exhibiting basophilic nuclei and little cytoplasm. ${ }^{4}$

Lymph nodes are dense and encapsulated component organs of the lymphatic system, which occur constantly in specific regions called lymphatic centers. These organs are usually reniform and vary in size, from $\sim 1 \mathrm{~mm}$ to several centimeters, and are formed by the capsule, the cortex, the medulla, the lymph nodules, and the thread. Lymph nodes function to produce lymphocytes, to filter the lymph, to phagocyte strange materials, and to produce antibodies. ${ }^{3}$

According to the authors ${ }^{4}$, the lymph node of a pig is characterized by being atypical, with the flow location reversed in the cortical and medullary tissues.

The lymph nodules, which are located inside the lymph nodes, usually in the peripheral region of the lymph nodes (cortex), are lymphocyte aggregates. An active, reactive and received

September 15, 2017

accepted

September 6, 2018

published online

October 31, 2018
DOI https://doi.org/

10.1055/s-0038-1675395. ISSN 2177-0298.
Copyright $\odot 2018$ by Thieme Revinter

Publicações Ltda, Rio de Janeiro, Brazil
License terms

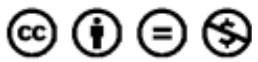


immunologically competent nodule is formed by the germinal center and the outer crown. The germinal center has several mature and immature cells, predominantly mature lymphocytes, lymphoblasts, plasma cells, dendritic cells, and macrophages. These centers are lighter than the outer crown due to the lower presence of cells and because they are clear. As lymphocytes are produced, they migrate peripherally to the outer crown, accumulating in the region. ${ }^{3}$

According to Saar et al, ${ }^{1}$ lymphocytes cluster into small aggregated lymph nodes, whose bright centers are classified as reaction centers or germinal centers. These dense aggregations of lymph tissue (nodules), some of which have reaction centers, are temporary structures, since their number and size fluctuate.

The importance of the present research is to provide greater knowledge about the morphological and histological aspects of agoutis, with emphasis on the cervical lymph ganglia, as well as to serve as a basis for the maintenance and preservation of this species.

The lymph nodes of different animal species may present anatomical and physiological differences. The objectives of the present work were the morphological analysis of the cervical lymph nodes of Dasyprocta prymnolopha, Wagler, 1831, commonly known as agouti, comparing them with typical lymph nodes of the animal kingdom. The accomplishment of this work is justified by the absence of bibliographic records about the lymph nodes of this wild species.

\section{Material and Methods}

All of the procedures related to the use of animals were performed according to the Ethical Council for Animal Use (CEUA, in the Portuguese acronym) and the Ethics and Animal Experimentation Committee of the Federal University of Piauí (CEEA-UFPI, in the Portuguese acronym), ensuring that the use of the animals occurred according to the principles governed by the guideline and law no. 11,749 , of 2008 , regulated by the decree no. 6,899 , of July 15,2009 . The use of wild animals also requires the approval of the Chico Mendes Institute of Biodiversity (SISBIO-ICMBio, in the Portuguese acronym), which also was respected. It should be noted that the organs of the animals not used in this research were reused by this institution of higher education for studies, to avoid unnecessary disposal, to respect the species studied, as well as to allow new scientific investigations.

For the accomplishment of this work, four agoutis ( $D$. prymnolopha, Wagler, 1831) were used, captured with the help of a puçá, a type of sieve used in fish farming, and weighed individually. The animals originated from the Center for the Study and Preservation of Wild Animals (NEPAS, in the Portuguese acronym) (certificate of registration IBAMA / PI No. 02 / 08-618), from the Agraria Sciences Center (CCA, in the Portuguese acronym) of the Universidade Federal do Piauí. The animals were then taken to the Histotechnic Laboratory in the Morphology Sector of the Health Sciences Center of the Universidade Federal do Piauí to perform the anesthetic procedure and the execution of macroscopic and microscopic practices.
The agoutis underwent previous analgesia with pethidine hydrochloride (Dolosal, Cristália, São Paulo, SP, Brazil) ${ }^{5}$ at a dose of $5 \mathrm{mg} / \mathrm{kg}$ intramuscularly (IM), used 15 minutes before the induction of anesthesia. A combination of 35 $\mathrm{mg} / \mathrm{kg}$ IM of ketamine hydrochloride (Dopalen, Vetbrands, São Paulo, SP, Brazil) and $1 \mathrm{mg} / \mathrm{kg}$ IM of xylazine hydrochloride (Antisedan, Vetbrands, São Paulo, SP, Brazil) were administered. After certifying that the anesthetic plan was appropriate, the agoutis were euthanized with an overdose of sodium thiopental intravenously until death due to cardiorespiratory arrest was observed. ${ }^{6}$

Finally, the dead agoutis were stored in formaldehyde, to preserve them for later collection of tissue. For the collection work, first the agouti was removed from the formaldehyde and bathed for 24 hours in running water. After that, they were placed on a support table, where, with the use of suitable surgical material, the process of search and removal of the lymph nodes located in the cranial and cervical regions of the animals was performed.

The lymph nodes were cleaned with distilled water, cut transversely with a microtomy razor and finally submitted to a routine histological procedure for subsequent H\&E staining. Finally, the slides were read under an optical microscope, in magnifications of $10 x, 20 x$ and $40 x$.

\section{Discussion and Results}

All cervical lymph nodes studied in the present work demonstrated morphological and histological similarities.

Morphologically, the cervical lymph nodes of agoutis exhibit a reniform shape, a few millimeters in size (-Fig. 1). According to Banks, ${ }^{3}$ lymph nodes are, in general, reniform organs and vary in size, from $\sim 1 \mathrm{~mm}$ to several centimeters. Therefore, there are no expressive morphological differences between the lymph nodes of agoutis and other animals in general.

The reading of the blades indicated that the cervical lymph nodes of the agouti have a morphology that resembles the description of a typical lymph node (-Fig. 2). Image A demonstrates the lymph node cortex containing the capsule (K) and the lymph nodules $\left(^{*}\right)$. It is possible to visualize the cortical region of the lymph nodules due to the darker coloring, involving their germinal center. Image B shows a more detailed view of the lymph nodes. In Image $C$, it is possible to observe with more clarity the defense cells of the lymph nodules.

According to Cesta, ${ }^{7}$ a lymph node is an organ arranged in cortex and medulla. The cortex consists of lymph nodules, surrounded by a diffuse lymphatic tissue. The lymph node is covered by a capsule of connective tissue, with few smooth and elastic muscle fibers.

According to Banks, ${ }^{3}$ lymph nodules, which are located inside the lymph nodes, usually in the peripheral region of the cortex, are lymphocyte aggregates. An active, reactive and immunologically competent nodule is formed by the germinal center and the outer crown. The germinal center has several mature and immature cells, predominantly mature lymphocytes, lymphoblasts, plasma cells, dendritic 


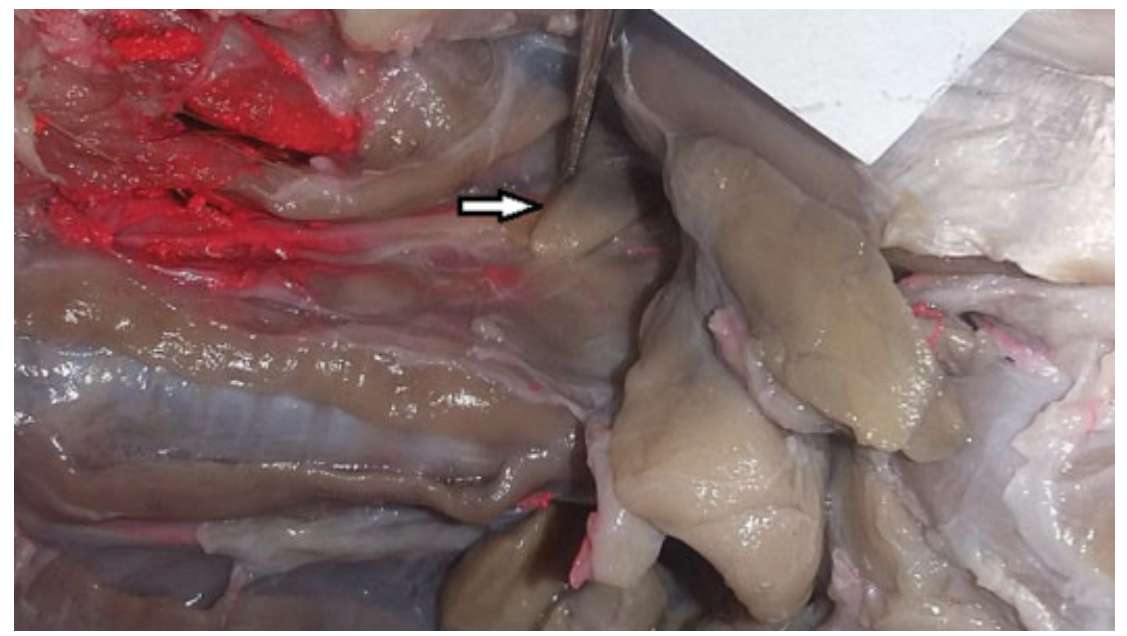

Fig. 1 Anatomical photograph of the cervical region dissection of agouti (Dasyprocta prymnolopha) evidencing the subpharyngeal lymph node of the right cervical chain (arrow). Personal archive.
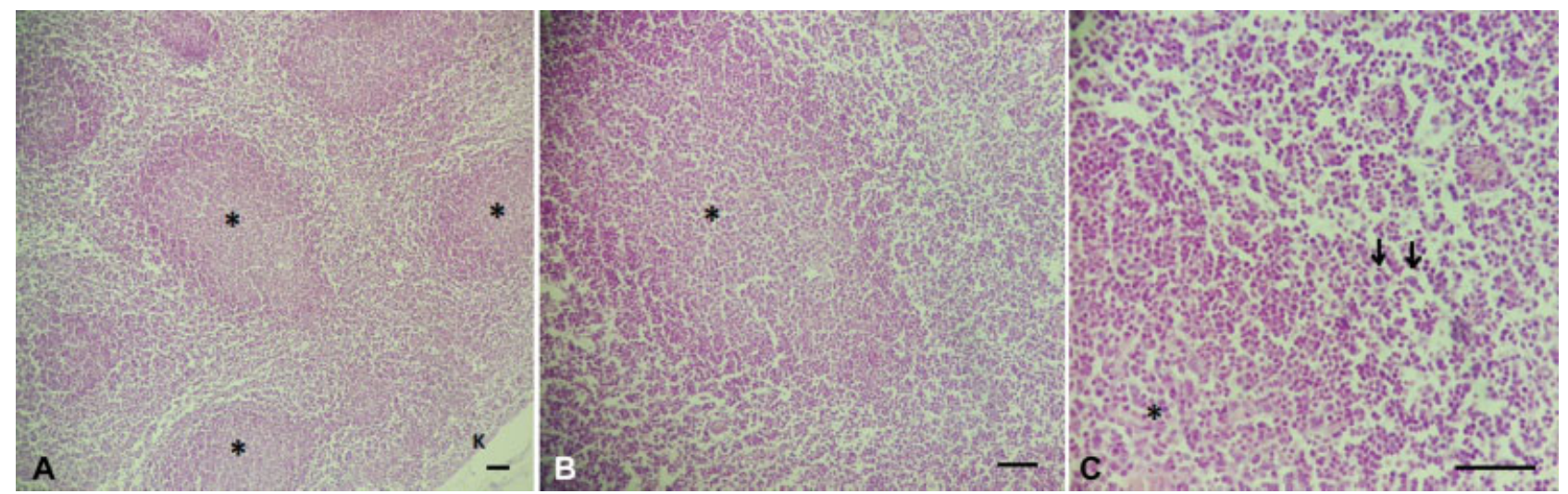

Fig. 2 Photomicrograph of the lymph node of the agouti (Dasyprocta prymnolopha) showing the cortical portion (Hematoxylin and Eosin staining) in magnifications of 10x, 20x and 40x. Personal Archive.

cells, and macrophages. These centers are lighter than the outer crown due to the lower presence of cells and because they are clear. As lymphocytes are produced, they migrate peripherally to the outer crown, accumulating in the region.

Therefore, the cranial and cervical lymph nodes of the agoutis did not demonstrate significant histological differences when compared with the lymph nodes typical of the animal kingdom.

\section{Conclusion}

After the analysis of the lymph nodes of D. prymnolopha, Wagler, 1831, it can be considered that there were no significant morphological differences between the cervical lymph nodes of the agoutis when compared with typical lymph nodes, denoting that the lymphatic system of this species behaves in a similar way to those of other animals.

The present work reached its objectives, thus allowing the improvement of the knowledge of the researchers about the morphological aspects of agoutis.

Studies on this animal must have continuity, since they can serve as a basis for its preservation, as well as for its maintenance in captivity, considering the biodiversity.

\section{Acknowledgments}

We thank the Universidade Federal do Piauí and the Study and Wildlife Preservation Nucleus (NEPAS-UFPI, in the Portuguese acronym).

\section{References}

1 Saar LI, Getty R. Sistema linfático em geral. Anatomia dos animais domésticos. 5 ed. Rio de Janeiro: Interamericana; 1981, v.1, cap. 12

2 Willard-Mack CL. Normal structure, function, and histology of lymph nodes. Toxicol Pathol 2006;34(05):409-424

3 Banks WJ. Histologia veterinária aplicada. 2 ed. São Paulo: Manole; 1991

4 Bacha Junior WJ, Bacha LM. Atlas colorido de histologia veterinária. 2 ed. São Paulo: Roca; 2003

5 Cavalcante MMAS. Anatomia e Morfologia do coração de cutia (Dasyprocta prymnolopha Wagner, 1831). Piauí: Universidade Federal do Piauí; 2017, 48p. [Dissertação de Mestrado em Ciências e Saúde]

6 Moura CRC, Diniz AN, Moura LS, Sousa FCA, Baltazar PI, Freire LD, Guerra PC, Sousa JM, Giglio RF, Pessoa GT, Sa RP, Alves FR. Cardiothoracic Ratio and Vertebral Heart Scale in Clinically Normal Black-Rumped Agoutis (Dasyprocta prymnolopha, Wagler 1831). J Zoo Wildl Med. 2015;2(46):314-319

7 Cesta MF. Normal structure, function, and histology of mucosa associated lymphoid tissue. Toxicol Pathol 2006;34(05):599-608 